\title{
Investigation of the Effectiveness of Dental Implant Osseointegration Characterized by Different Surface Types
}

\author{
Natalia Astashina ${ }^{1}$, Alex Lugovskoy ${ }^{2}$, Aleksey Kossenko ${ }^{2}$, Svetlana Lugovskoy ${ }^{2, *}$, \\ Gennadi Rogozhnikov ${ }^{1}$ and Michael Zinigrad ${ }^{2}$ \\ 1 The Department of Dentistry, Perm State Medical University named after E.A. Wagner, \\ 26 Petropavlovskaya St., Perm 614990, Russia; caddis@mail.ru (N.A.); Ortstom_pgmu@mail.ru (G.R.) \\ 2 Chemical Engineering Department, Ariel University, Scientific Park, Ariel 40700, Israel; \\ lugovsa@ariel.ac.il (A.L.); kossenko@ariel.ac.il (A.K.); mzinigrad@ariel.ac.il (M.Z.) \\ * Correspondence: svetlanalu@ariel.ac.il; Tel.: +972-3-906-6217
}

Academic Editor: Laichang Zhang

Received: 6 April 2017; Accepted: 25 May 2017; Published: 2 June 2017

\begin{abstract}
Different surfaces were obtained by Plasma Electrolytic Oxidation (PEO) of the Ti-6Al-4V alloy; followed by hydrothermal treatment (HT). The surfaces were studied by scanning electron microscopy (SEM); Energy Dispersive Spectroscopy (EDS); X-ray Diffraction (XRD); Brunauer-Emmett-Teller (BET) absorption and abrasion wear tests. The resulting surface contains hydroxyapatite (HA); which contributes to superior implant osseointegration. Treated implants were introduced into rabbits and their osseointegration was studied after two and six months. It was established that implant surface area increases due to pore formation. Pore formation and hydroxyapatite on the surface of the implant qualitatively change contact osseogenesis processes with reduced duration of osseointegration of implants. The treatment of the surface of the implants by the combination of PEO and HT provided better results in the medico-biological investigations than PEO alone. Abrasion tests demonstrated that the HA will be preserved after the procedure of implantation; ensuring effective osseointegration.
\end{abstract}

Keywords: plasma electrolytic oxidation; hydroxyapatite; oxide layers; biomaterials; osseointegration

\section{Introduction}

The effectiveness of dental implantation and the long-term functioning of intraosseous implants are largely determined by integration conditions. A basic factor influencing the rate and quality of osseointegration is the density of recipient bone tissue. As bone density decreases, so does its strength and ability to accept foreign bodies, including any implantation systems. In "soft" types of bone (D4 bone according to Misch's classification [1]) osseointegration processes can be improved by using an intermediary layer composed of a material with properties of sufficiently high adhesion to both metal and bone tissue [2]. The employment of a hydroxyapatite coating provides a significant increase in the contact area between implant and bone, producing noticeable improvement in short-range viability indices as compared to "clean" titanium implants [3]. It has been shown that coating the surface of titanium implants with a layer of hydroxyapatite [4] increases the rate of adaptation of bone tissue to the implants, guarantees sufficient initial fixation rigidity of the implanted structures, and stimulates growth of mature bone tissue along with improvement of its quantitative and qualitative indicators. In addition, the bone surrounding HA-coated implants is strengthened in comparison to structures lacking a modified layer. To improve quality and long-term effectiveness of dental implantation in bone tissue of type D4, researchers recommend using implants with an osteoinductive 
hydroxyapatite coating [5-9]. Here we will compare the effectiveness of osseointegration of dental implants on whose surfaces hydroxyapatite (HA) layers were produced by several combinations of Plasma Electrolytic Oxidation followed by a hydrothermal treatment.

\section{Experimental}

To improve the effectiveness of the osseointegration of titanium implants, we developed a technology involving the use of an intermediary material with sufficiently high adhesion to both metal and bone tissue. The essence of this method is a fusion of plasma electrolytic oxidation (PEO) of titanium (Ti-6Al-4V alloy) and a method of hydrothermal treatment which ultimately ensures the formation of a phase of hydroxyapatite [10]. The details of the method were published elsewhere [11]. The hydrothermal treatment was carried out under different conditions: at an alkaline $\mathrm{pH}$ of the solution and using different treatment times ( 2 and $4 \mathrm{~h}$ ).

The conductivities and $\mathrm{pH}$ of the electrolytes were measured by a YK-2005WA pH/CD meter (Lutron Electronic Enterprise Co., LTD., Taipei, Taiwan), with the thickness of the oxide layers measured by a micrometer, a CM-8825 coating thickness gauge (Mextech Technologies India, Mumbai, Maharashtra, India), and a scanning electron microscopy (JEOL JSM-6510LV SEM, Jeol, Tokyo, Japan). The surface morphology, structure, and composition were examined on a JEOL JSM-6510LV SEM equipped with an NSS7 EDS (Thermo Fisher Scientific, Waltham, MA, USA) analyzer (the Proza Phi-Rho-Z correction method was used for the quantitative analysis). Cross-section samples prepared according to standard metallographic protocols were used for SEM, Energy Dispersive Spectroscopy (EDS), and X-ray Diffraction (XRD). A PANalytical X'Pert Pro X-ray diffractometer (XRD, PANalytical B.V., Eindhoven, The Netherlands) in $\mathrm{Cu} K \alpha$ radiation $(\lambda=0.154 \mathrm{~nm})$ was used with full pattern identification by the X'Pert HighScore Plus software package, version 2.2e (2.2.5) (PANalytical B.V., Eindhoven, The Netherlands), from PANalytical B.V. Materials identification and analysis were performed using PDF-2 Release 2009 (Powder Diffraction File). Phase analysis identification was performed by XRD at $40 \mathrm{kV}$ and $40 \mathrm{~mA}$. The XRD patterns were recorded in the grazing incidence $X$-ray diffraction (GIXD) geometry with $\alpha=1^{\circ}$ and $5^{\circ}$ in the $20-80^{\circ}$ range (the step size was $0.05^{\circ}$ and the time per step was $2 \mathrm{~s}$ ).

The Brunauer-Emmett-Teller (BET) method, a basic approach for specific surface measurement $[12,13]$, was used to characterize the nanomaterial obtained. The surface areas were measured by the BET method using a Micromeritics ASAP 2020 instrument (Micromeritics, Norcross, GA, USA). Fifteen-point adsorption isotherms of nitrogen were collected in the $\mathrm{P} / \mathrm{P} 0$ relative pressure range from 0.05 to 0.30 ( $\mathrm{P0}$ is the saturation pressure) at $-196{ }^{\circ} \mathrm{C}$. Prior to analysis, each sample was degassed under vacuum at $200{ }^{\circ} \mathrm{C}$ for $4 \mathrm{~h}$.

The abrasion wear of the obtained surface layer was tested on a 5750 Linear Abraser by Taber Industries (Taber Industries, New York, NY, USA). A fragment of spongy bone tissue from a rabbit mandible served as the rubbing body.

To perform the medico-biological tests, samples (ASTM F1983: Standard Practice for Assessment of Compatibility of Absorbable/Resorbable Biomaterials for Implant Applications) of a titanium alloy with a well-formed osteoinductive surface containing hydroxyapatite were prepared, and two groups of experimental animals (namely, rabbits) were assembled.

The observation group consisted of 10 animals, with two implants inserted in each animal. The first type of implant was a structure formed by plasma electrolytic oxidation without hydrothermal treatment (without a layer of hydroxyapatite). The second type of implant was a structure formed by plasma electrolytic oxidation followed by the formation of a layer of hydroxyapatite on the surface.

Each implantable sample was prepared and subjected to sterilization treatment in accordance with the technology used for the finished product. Samples of the test and control materials were implanted under identical conditions in appropriate anatomical locations.

The duration of the experiment was chosen longer than that required for the achievement of the stable phase of the biological reaction. The first group of animals (five specimens with 10 
implanted structures) was withdrawn from the experiment at the end of two months after implantation. The second group (five specimens with 10 implanted structures) was withdrawn at the end of six months after the implantation procedure. According to the experimental methodology developed, 10 test samples and 10 control samples were studied for each implantation period. The material for the histological study of the reaction of the tissue in the contact zone with an implant was obtained from the animals by excising portions of the implant-bone assembly six months after introduction of the implant. The material was fixed in a neutral $10 \%$ solution of formalin in a phosphate buffer ( $\mathrm{pH}$ 7.4). Decalcification was performed by a solution of Trilon B over the course of four months with daily replacement of the solution and monitoring of the $\mathrm{pH}$. After completion of the decalcification, the blocks were impregnated with a solution of celloidin and castor oil and were then cast into paraffin saturated with wax according to the conventional procedure. The finished sections were stained with hematoxylin and eosin.

\section{Results and Discussion}

An amorphous layer of titanium dioxide formed using the plasma electrolytic oxidation method, containing phosphorus and calcium in the form of calcium titanate and titanium diphosphate. The thickness of the obtained amorphous layer is equal to 9-15 $\mu \mathrm{m}$. It was established that the morphology of this surface scarcely depends on the treatment time [11]. The X-ray powder diffraction analysis performed on the coating (Figure 1) showed the relative amounts of calcium and phosphorus as the principal components of the obtained hydroxyapatite crystals.

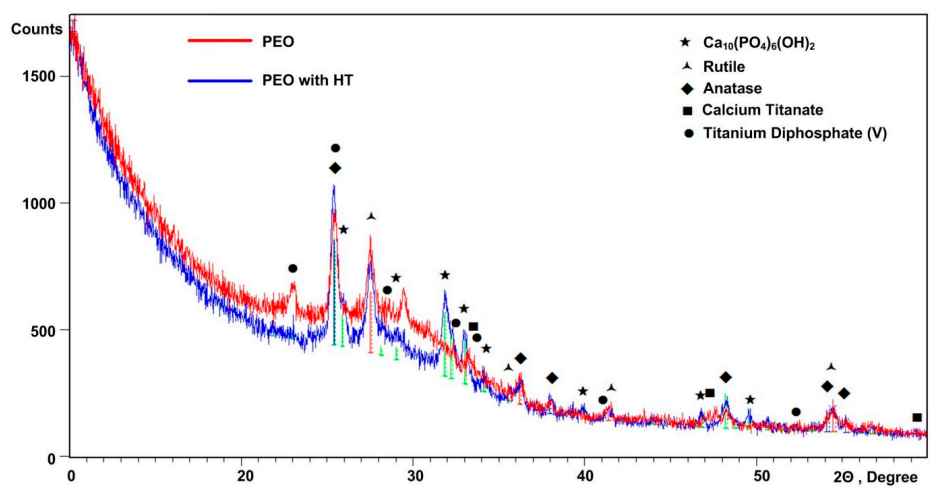

Figure 1. X-ray diffraction (XRD) analysis: Sample after Plasma Electrolytic Oxidation (PEO) and sample after PEO and hydrothermal treatment $(\mathrm{HT})$.

The results of the investigation using EDS, after each treatment stage (at three points on the sample surface), are presented in Figure 2 and Table 1.

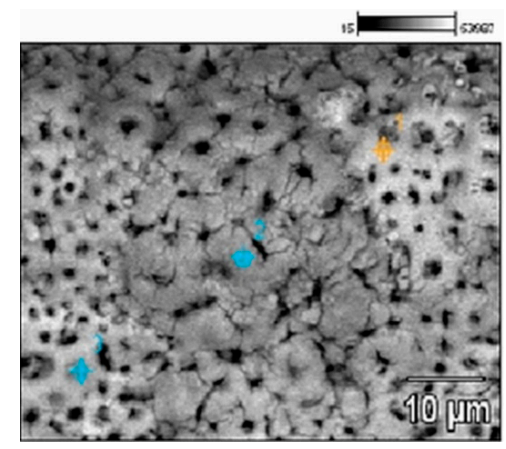

Figure 2. Energy Dispersive Spectroscopy (EDS) analysis taken from three different points (marked 1, 2 and 3) of a surface of a specimen treated by PEO for $20 \mathrm{~min}$. 
Table 1. Results of the EDS analysis of the elements (oxygen, phosphorus, calcium, and titanium) in wt. \%.

\begin{tabular}{ccccc}
\hline No. & O-K & P-K & Ca-K & Ti-K \\
\hline 1 & $47.28 \pm 1.17$ & $6.61 \pm 0.19$ & $11.32 \pm 0.32$ & $34.79 \pm 0.58$ \\
2 & $32.86 \pm 0.78$ & $13.00 \pm 0.31$ & $21.59 \pm 0.63$ & $22.55 \pm 0.68$ \\
3 & $28.40 \pm 0.76$ & $11.24 \pm 0.28$ & $18.07 \pm 0.59$ & $32.28 \pm 0.75$ \\
\hline
\end{tabular}

The $\mathrm{Ca} / \mathrm{P}$ ratio on the surface was 1.7 , in which the mean ratios $\mathrm{Ca} / \mathrm{P}=1.67[14,15]$ were indicated. The study of the processes involved in the formation of hydroxyapatite crystals on the titanium surface provides evidence that their inception depends on the number of surface hydroxyl groups present [4]. As seen in Figure 2, the performance of plasma electrolytic oxidation influences the porosity of the sample. Crystals consisting mainly of a small quantity of hydroxyapatite, titanium diphosphate, and calcium titanate ultimately grow within pores that are formed on the surface of the sample after $20 \mathrm{~min}$ of treatment (Figure 2). The degree of crystallinity influences the dissolution and biological behavior of the hydroxyapatite layers.

SEM images of the oxide layer after hydrothermal treatment are presented in Figure 3.

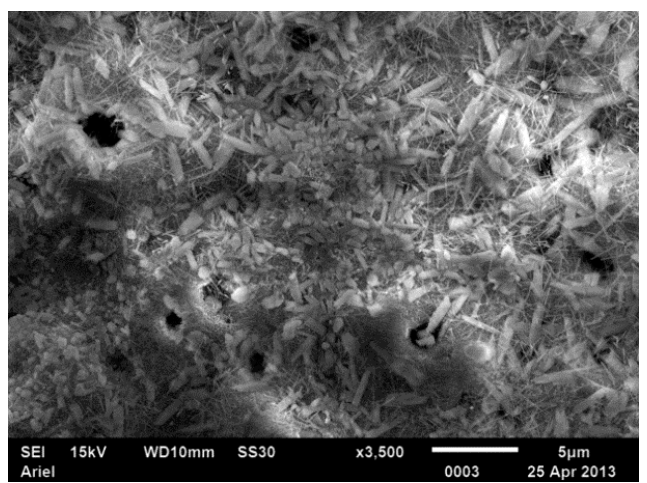

(a)

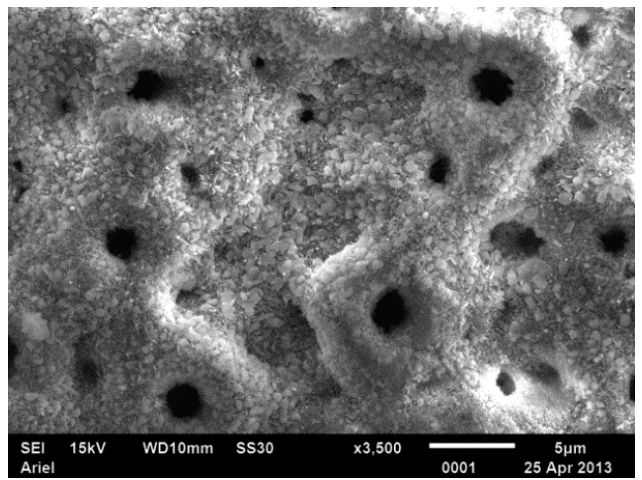

(b)

Figure 3. SEM images of the oxide layer after hydrothermal treatment (for $\mathrm{pH} 11$ and different treatment times). Crystals have grown on the surface after the hydrothermy (cf. Figure 2, where only PEO was made). (a) pH 11 (2 h of hydrothermal treatment); (b) pH 11 (4 h of hydrothermal treatment).

The maximum quantity of the crystalline structure and hydroxyapatite was obtained at $\mathrm{pH} 11$ after hydrothermal treatment for $2 \mathrm{~h}$ (Figure 3a).

Table 2 presents the results of a comparative analysis according to the BET method.

Table 2. The (Brunauer-Emmett-Teller) BET method results for different samples.

\begin{tabular}{ccc}
\hline Sample & BET Surface Area $\left(\mathbf{m}^{\mathbf{2}}\right)$ & BET Surface Area $\left(\mathbf{m}^{\mathbf{2}} \mathbf{g}\right)$ \\
\hline Ti-1 pure (sample 1) & - & - \\
Ti-2 after PEO (sample 2) & $0.0539 \pm 0.0055$ & $1.65 \pm 0.17$ \\
Ti-4 pH 11 (sample 4) & $56.92 \pm 0.73$ & $2013.54 \pm 25.56$ \\
\hline
\end{tabular}

As can be seen from the BET results, the most thoroughly developed surface area was obtained after the hydrothermal treatment at $\mathrm{pH} 11$. At the same time, the $\mathrm{Ca} / \mathrm{P}$ ratio did not vary over the course of the entire hydrothermal treatment process, and the treatment altered only the shape and size of the hydroxyapatite crystals.

Three series of experiments were performed to study the abrasion wear of the surface layer obtained: 1—without a load (Figure 4); 2-with a $250 \mathrm{~g}$ load (Figure 5); 3-with a $750 \mathrm{~g}$ load (Figure 6). The experimental results were investigated on the SEM. 


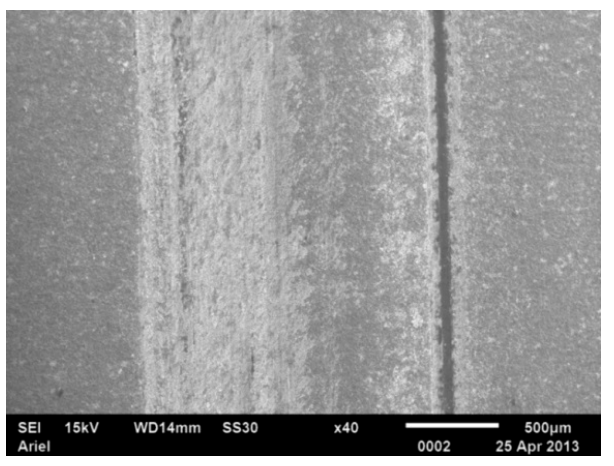

(a)

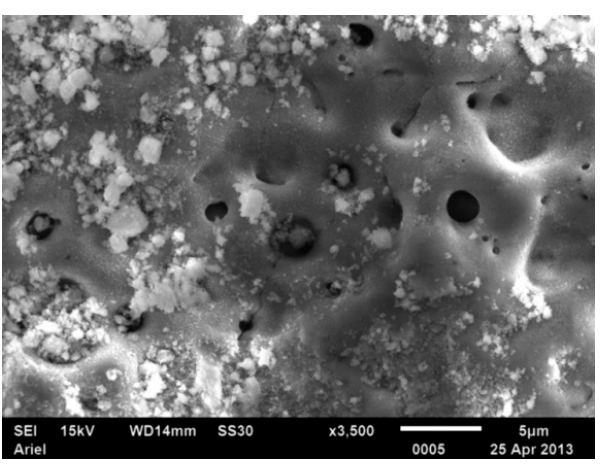

(b)

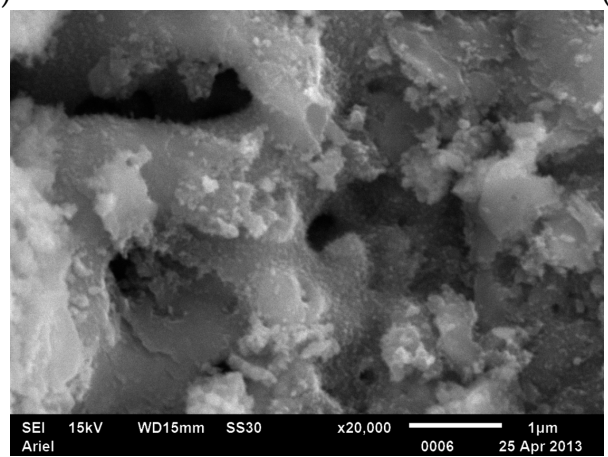

(c)

Figure 4. SEM photographs after abrasive wear tests without a load at different magnifications: (a) $40 \times$, (b) $3500 \times$, (c) $20,000 \times$.

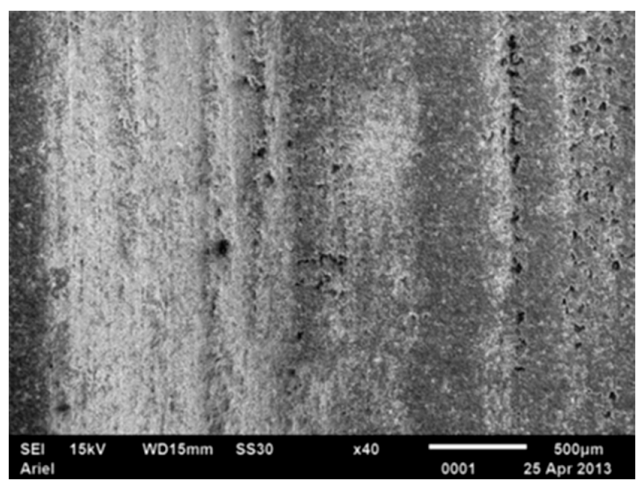

(a)

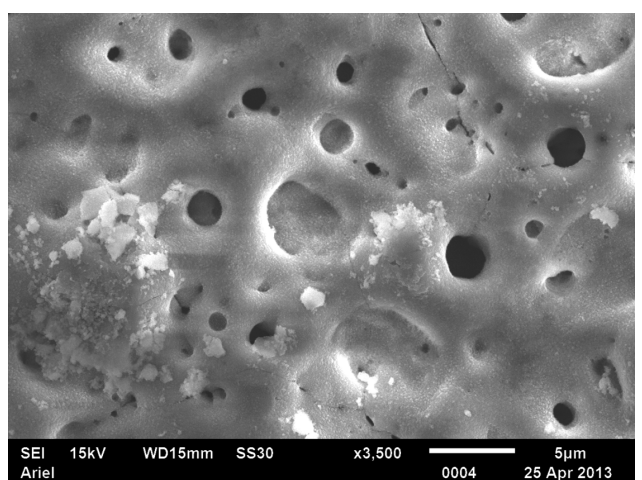

(b)

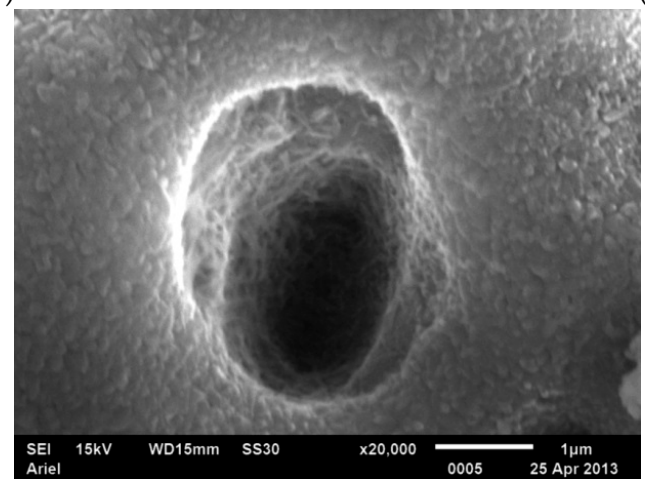

(c)

Figure 5. SEM photographs after abrasive wear tests ( $250 \mathrm{~g}$ load) at different magnifications: (a) $40 \times$, (b) $3500 \times$, (c) $20,000 \times$. 


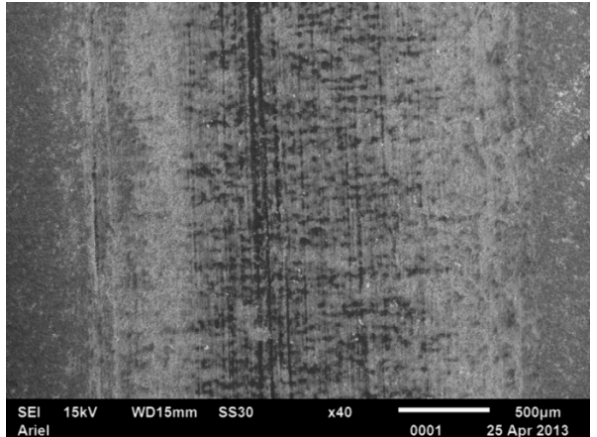

(a)

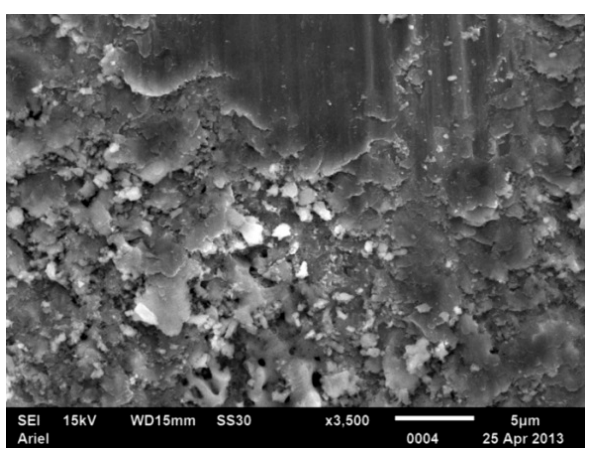

(b)

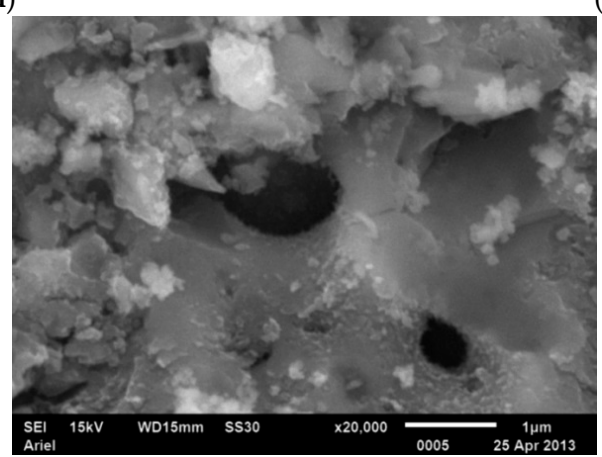

(c)

Figure 6. SEM photographs after abrasive wear tests (750 g load) at different magnifications: (a) $40 \times$, (b) $3500 \times$, (c) $20,000 \times$. White color marks are "smearing of bone" on the sample.

It was established from the results of the abrasive wear testing that the rubbing body is severed by peaks on the porous surface, while there are no fragments of the rubbing body in the depressions (pores). In the pores, crystals of hydroxyapatites are detectable in sufficient quantity (Figure 4). This enables us to conclude that, when an implant treated according to our technology is inserted into bone, a large part of the hydroxyapatite layer will be preserved, ensuring effective osseointegration.

The results of the evaluation of contact osseogenesis in the first group of experimental animals showed that a part of the implant is surrounded by an intermediate layer of connective tissue, along the perimeter of which there is regenerating coarse-fibered bone tissue surrounded by laminar bone without the pronounced morphological organization usually characteristic of normal bone structure. Largely incomplete processes that lead to the production of laminar bone tissue with the formation of coarse-fibered bone, are still observable (Figure 7).

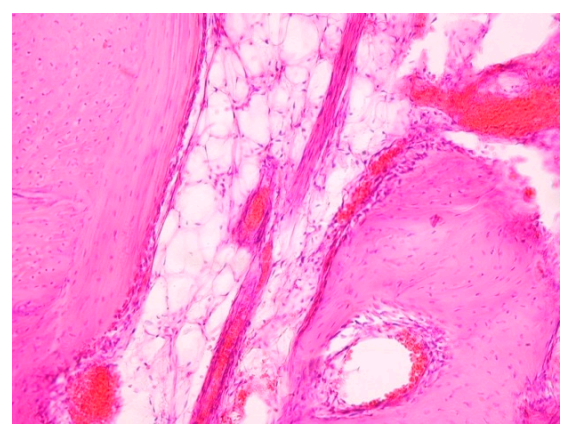

Figure 7. Morphological pattern of the tissue surrounding an implant of the first type. Individual trabecula of coarse-fibered bone. Two months after implantation. $400 \times$.

An analysis of the morphological pattern for the implantation of samples of the second type (with a surface layer modified by hydroxyapatite crystals) observed two months after implantation 
showed that the bone structures in some zones come into direct contact with the hydroxyapatite crystals. In this case, the bone matrix, which consists of well-formed coarse-fibered bone, grows into irregularities on the relief of the implant surface. The regions of contact of the implant with bone reach $55-60 \%$, their dimensions range from 150 to $800 \mu \mathrm{m}$, and they are separated by vessels of various sizes filled with blood. Tiny, newly formed vessels and small bone trabeculae with different degrees of mineralization are frequently seen on the surface of the implant (Figure 8). Ordinary laminar bone tissue, which is distinguished only by its large excess of blood, is located along the periphery away from them.

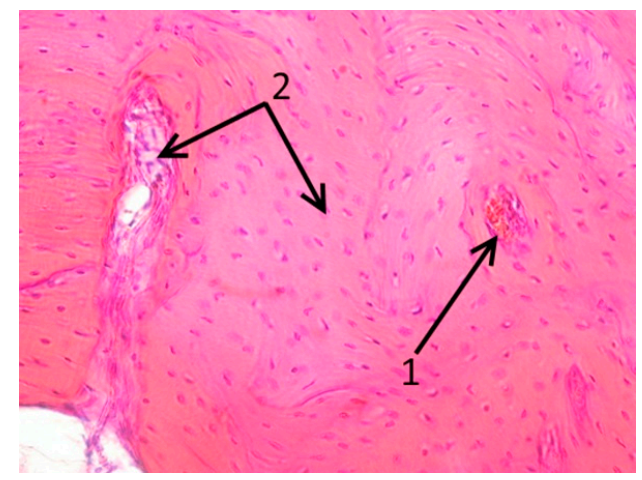

Figure 8. The morphological pattern of the tissue surrounding an implant of the second type. Newly formed laminar bone tissue. Two months after implantation. $400 \times$. 1: a blood vessel. 2: Bone tissues of different ages.

When microscopic slides of samples of the first type taken from the bone tissue of experimental animals six months after the beginning of the experiment were evaluated, the presence of a connective tissue capsule around the implant was discovered. There is a distinct layer of coarse-fibered bone (Figure 9). Some slowing of the development and formation of typical laminar bone tissue is noted.

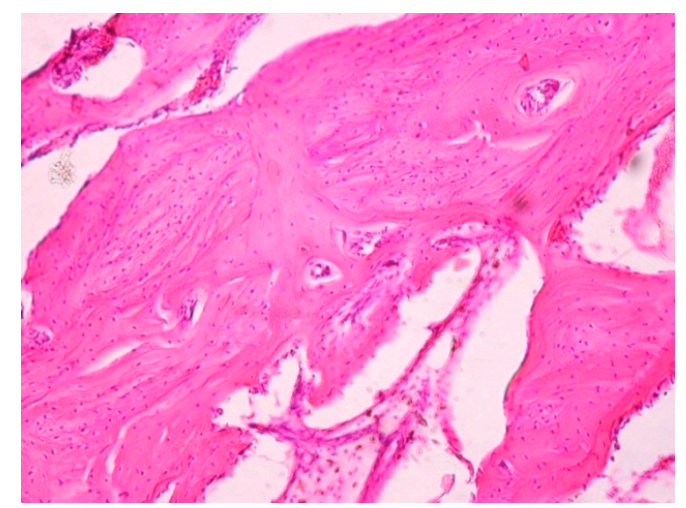

Figure 9. Morphological pattern of the tissue surrounding an implant of the first type. Coarse-fibered bone tissue and newly formed laminar bone tissue. Six months after implantation. $400 \times$.

When microscopic slides of samples of the second type taken from bone tissue of experimental animals six months after the beginning of the experiment were evaluated, it was discovered that the contact region between the bone tissue and the implant broadened significantly during this period. A large part of the existing regenerated tissue is composed of mature laminar bone tissue (Figure 10), which is usually permeated by blood vessels. There is direct contact between the bone and the implant. The content of coarse-fibered bone and connective tissue decreased to a great extent, and the width of the latter in the direction from the implant to the mature bone does not exceed 500-1000 $\mu \mathrm{m}$. The newly formed bone is actively mineralized in the direction toward the implant. 


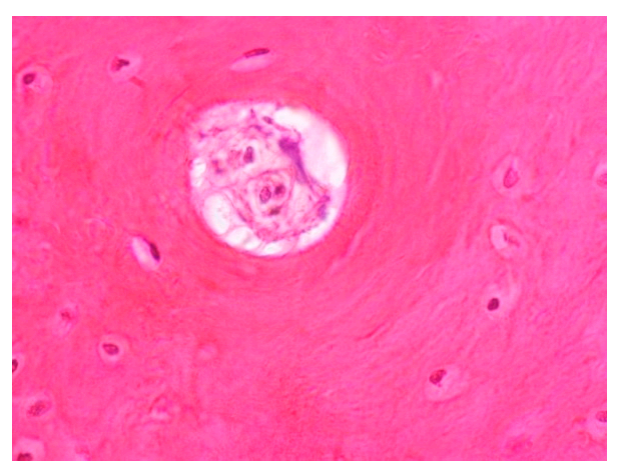

Figure 10. Morphological pattern of the tissue surrounding an implant of the second type. Newly formed osteon. Six months after implantation. $400 \times$.

As a result of the morphological investigations performed, it was established that implants of the second type have a slight stimulating effect on the surrounding bone tissue. When the local response of the surrounding tissue was evaluated, the requirements of ASTM F1983 (Standard Practice for Assessment of Compatibility of Absorbable/Resorbable Biomaterials for Implant Applications), which include intensity of neovascularization, degree of development of connective tissue, and presence of a fatty infiltrate, were taken into account. In all of the samples, the tests for local effects after implantation (ISO 10993-6:2009) provided the value of up to 8.9 points and fell in the 3.0-8.9 range. In $83 \%$ of the samples, the tissue reaction was at 4.5 points, and in $17 \%$ it was at eight points. At the site of contact between the bone tissue and the implant, a group of four to seven capillaries surrounded by individual cells of fibroblastic differentiation was often verified. The fibroblasts were in a state of moderate activity, which was expressed by the development of zones of connective tissue, but the extent of their development was small. In conclusion, according to the conditions of the present experiment, the samples investigated were recognized as mild stimulants (3.0-8.9).

The technology of treating the surface of the implants by PEO followed by hydrothermal treatment provided better results in the medico-biological investigations in comparison to implants not treated by this method.

An analysis of the results of the preclinical medico-biological analytical investigations performed to study the properties of dental implants, prepared with the use of the technology developed herein and with the formation of a modified osteoinductive surface, showed that contact osseogenesis processes are qualitatively altered with shortening of osseointegration times of the implants.

As a result of our investigation, the desirability of using a modified design of dental implants made from nanostructured titanium with an osteoinductive surface for implantation into type IV bone tissue has been demonstrated.

\section{Conclusions}

(1) The procedure of plasma electrolytic oxidation with the selected parameters results in the formation of a porous, relatively amorphous, oxide layer containing trace amounts of hydroxyapatite along with appreciable amounts of titanium diphosphate (a precursor of hydroxyapatite) and other oxide phases in an assigned ratio on the titanium surface.

(2) Subsequent hydrothermal treatment results in the formation of a crystalline layer composed of hydroxyapatite crystals of the required size and shape. Conversion of the precursor into hydroxyapatite occurs in this stage.

(3) On the basis of the results of abrasive wear testing, it was established that the rubbing body is severed by peaks on the porous surface, while there are no fragments of the rubbing body in the depressions (pores). Therefore, when an implant using this technology is inserted into bone, a significant part of the hydroxyapatite layer will be preserved, ensuring effective osseointegration. 
(4) Using these approaches and technologies qualitatively alters the process of contact osseogenesis, shortening the duration of osseointegration implantation.

Acknowledgments: The research was financially supported by the Ministry of Education of the Perm Region as a research project-“"Development of biologically inert nanomaterials and advanced technologies in dentistry within the holiatry program for patients with defects of dentition and jaws".

Author Contributions: Natalia Astashina performed all in vivo experiments and the analyses of those, Alex Lugovskoy performed the generalization of results and wrote the paper, Aleksey Kossenko made XRD examinations and PEO treatments, Svetlana Lugovskoy made general and hydrothermal treatment and wrote the paper, Michael Zinigrad and Gennadi Rogozhnikov executed general leadership.

Conflicts of Interest: The authors declare no conflict of interest.

\section{References}

1. Misch, C.E. Density of bone: effect on treatment plans, surgical approach, healing, and progressive loading. Int. J. Oral Implantol. 1990, 6, 23-31. [PubMed]

2. Martinez, H.; Davarpanah, M.; Missika, P.; Celletti, R.; Lazzara, R. Optimal implant stabilization in low density bone. Clin. Oral Implants Res. 2001, 12, 423-432. [CrossRef] [PubMed]

3. Fugazzotto, P.A.; Wheeler, S.L.; Lindsay, J.A. Success and failure rates of cylinder implants in type IV bone. J. Periodontol. 1993, 64, 1085-1087. [CrossRef] [PubMed]

4. Lugovskoy, A.; Lugovskoy, S. Production of hydroxyapatite layers on the plasma electrolytically oxidized surface of titanium alloys. Mater. Sci. Eng. C 2014, 43, 527-532. [CrossRef] [PubMed]

5. Blok, M.S.; Finger, I.M.; Fontenot, M.G.; Kent, J.N. Loaded hydroxyapatite-coated and grit-blasted titanium implants in dogs. Int. J. Oral Maxillofac. Implants 1989, 4, 219-225.

6. Gammage, D.D.; Bowman, A.E.; Meffert, R.M.; Cassingham, R.J;; Davenport, W.A. A histologic comparison of the interface in loaded IMZ and integral implants. Int. J. Periodontics Restor. Dent. 1990, 10, 125-135.

7. Ochi, S.; Morris, H.F.; Gillette, W.; Glasscock, W.; Lambert, P.; Lauciello, F.; Stoffer, W.; Weir, D. Mobility differences among implant designs and coatings at uncovering. J. Dent. Res. 1994, 73, 138.

8. Cooc, S.D.; Kay, J.F.; Thomas, K.A.; Jarcho, M. Interface mechanics and histology of titanium and hydroxylapatite-coated titanium for dental implant application. Int. J. Oral Maxillofac. Implants 1987, $2,1-15$.

9. Matsui, Y.; Ohnok, M.K.; Yamagata, K. Experimental study of high velocity flame sprayed hydroxyapatite coated and noncoated titanium implants. Int. J. Oral Maxillofac. Implants 1994, 9, 397-404.

10. Dicu, M.; Matei, A.; Abrudeanu, M.; Ducu, C. Synthesis and properties of the porous titania coatings formed on titanium by plasma electrolytic oxidation for biomedical application. J. Optoelectron. Adv. Mater. 2011, 13, 324-331.

11. Kossenko, A.; Lugovskoy, S.; Astashina, N.; Lugovskoy, A.; Zinigrad, M. Effect of time on the formation of hydroxyapatite in PEO process with hydrothermal treatment of the Ti-6Al-4V alloy. Glass Phys. Chem. 2013, 39, 639-642. [CrossRef]

12. Brunauer, S.; Emmett, P.H.; Teller, E. Adsorption of Gases in Multimolecular Layers. J. Am. Chem. Soc. 1938, 60, 309-319. [CrossRef]

13. Sing, K.S.W. Adsorption methods for the characterization of porous materials. Adv. Coll. Interface Sci. 1998, 76-77, 3-11. [CrossRef]

14. Wang, H.; Lee, J.K.; Moursi, A.; Lannutti, J.L. Ca/P ratio effects on the degradation of hydroxyapatite in vitro. J. Biomed. Mater. Res. A 2003, 67, 599-608. [CrossRef] [PubMed]

15. Salas, J.; Benzo, Z.; Gonzalez, G.; Marcano, E.; Gómez, C. Effect of Ca/P ratio and milling material on the mechanochemical preparation of hydroxyapaptite. J. Mater. Sci. Mater. Med. 2249, 20, 2249-2257. [CrossRef] [PubMed]

(C) 2017 by the authors. Licensee MDPI, Basel, Switzerland. This article is an open access article distributed under the terms and conditions of the Creative Commons Attribution (CC BY) license (http:/ / creativecommons.org/licenses/by/4.0/). 